\title{
Glandular Lesions of the Uterine Cervix
}

Richard J. Zaino, M.D.

Department of Pathology, M.S. Hershey Medical Center, Pennsylvania State University, Hershey, Pennsylvania

During the past 20 years, pathologists have more carefully examined and more precisely classified glandular lesions of the endocervix, largely reflecting increased concerns about the diagnosis and pathogenesis of adenocarcinoma of the cervix. This review of glandular lesions of the cervix focuses on the following six issues surrounding the histologic diagnosis of the more common types of adenocarcinoma of the endocervix and their mimics: (1) the classification and recognition of preinvasive glandular lesions, (2) the distinction of invasive from preinvasive adenocarcinoma, (3) the definition and significance of microinvasive adenocarcinoma, (4) the epidemiology and pathogenesis of adenocarcinoma, (5) the identification and behavior of the more common subtypes of invasive adenocarcinoma, and (6) the recognition of benign lesions that mimic adenocarcinoma.

It is the author's opinion that most in situ and invasive adenocarcinomas of the cervix can be recognized and distinguished from benign mimics. In contrast, glandular dysplasia and microinvasive adenocarcinoma of the cervix are currently ill-defined and irreproducible terms that should not be used for diagnostic purposes. Although only brief descriptions of the biologic behavior of the various lesions and their therapy are included in this review, certain variants of endocervical adenocarcinoma have distinctive behaviors and should be classified appropriately to provide prognostication and help to guide therapy.

KEY WORDS: Adenocarcinoma, Adenocarcinoma in situ, Cervix, Cervix neoplasm, Cervix nonneoplastic

Mod Pathol 2000;13(3):261-274

Copyright (C) 2000 by The United States and Canadian Academy of Pathology, Inc.

VOL. 13, NO. 3, P. 261, 2000 Printed in the U.S.A.

Date of acceptance: November 8, 1999.

Address reprint requests to: Richard J. Zaino, M.D., Department of Pathology, M.S. Hershey Medical Center, 500 University Drive, P.O. Box 850, Hershey, PA 17033; fax: 717-531-7741.
The relative or absolute increase in the frequency of adenocarcinoma of the cervix in the 1980s, coupled with the introduction of the endocervical brush, broom, and other endocervical sampling devices, has stimulated us to examine more carefully and classify more precisely the lesions of the endocervix. It is no longer possible to discuss the pathogenesis and behavior of the complete spectrum of glandular lesions of the uterine cervix in one lecture. Instead, this article addresses the following six pragmatic issues surrounding the diagnosis of adenocarcinoma of the endocervix and its mimics:

1. The classification and recognition of preinvasive glandular lesions

2. The distinction of invasive from preinvasive adenocarcinoma

3. The definition and significance of microinvasive adenocarcinoma

4. The epidemiology and pathogenesis of adenocarcinoma

5. The identification and behavior of the more common subtypes of invasive adenocarcinoma

6. The recognition of benign lesions that mimic adenocarcinoma

\section{CLASSIFICATION OF PREINVASIVE ADENOCARCINOMA OF THE CERVIX}

Although the World Health Organization's classification of tumors of the cervix includes among the lexicon of preinvasive tumors of the cervix glandular atypia, glandular dysplasia (atypical hyperplasia), and adenocarcinoma in situ (1), the distinguishing morphologic features for these lesions remain unsettled. At the lower end of the spectrum, reactive inflammatory changes and tubal metaplasia must be distinguished from preinvasive cancer; in the middle, one might consider grading the severity of lesions; and at the upper end of the spectrum, criteria for invasion must be defined. No pathognomonic histologic characteristics are intuitively obvious, and, consequently, a plethora of definitions have been presented for many of these lesions but without widespread acceptance. 


\section{Adenocarcinoma In Situ}

Adenocarcinoma in situ (AIS) of the cervix was first described by Friedell and McKay (2) in 1953, with few subsequent investigations of this entity during the next 20 years. In the late 1970s, there was renewed interest in characterizing precursor lesions of invasive adenocarcinoma with an intent either to invoke a unifying theory of a common subcolumnar reserve cell for all types of cervical cancer (3) or to categorize lesions in a fashion analogous to precursors of squamous carcinoma of the cervix (4).

AIS has consistently been characterized by the following histologic features: (1) preservation of normal glandular architecture; (2) involvement of part or all of the epithelium lining glands or forming the surface; (3) nuclear enlargement, coarse chromatin, small single or multiple nucleoli; (4) increased mitotic activity; and (5) variable stratification of nuclei. Cytoplasmic mucin may be either reduced in quantity or abundant (4) (Figs. 1, 2).

Good evidence supports the existence of AIS as a precursor lesion for invasive adenocarcinoma, as follows: (1) AIS is diagnosed in the population that is approximately 10 to 15 years younger than

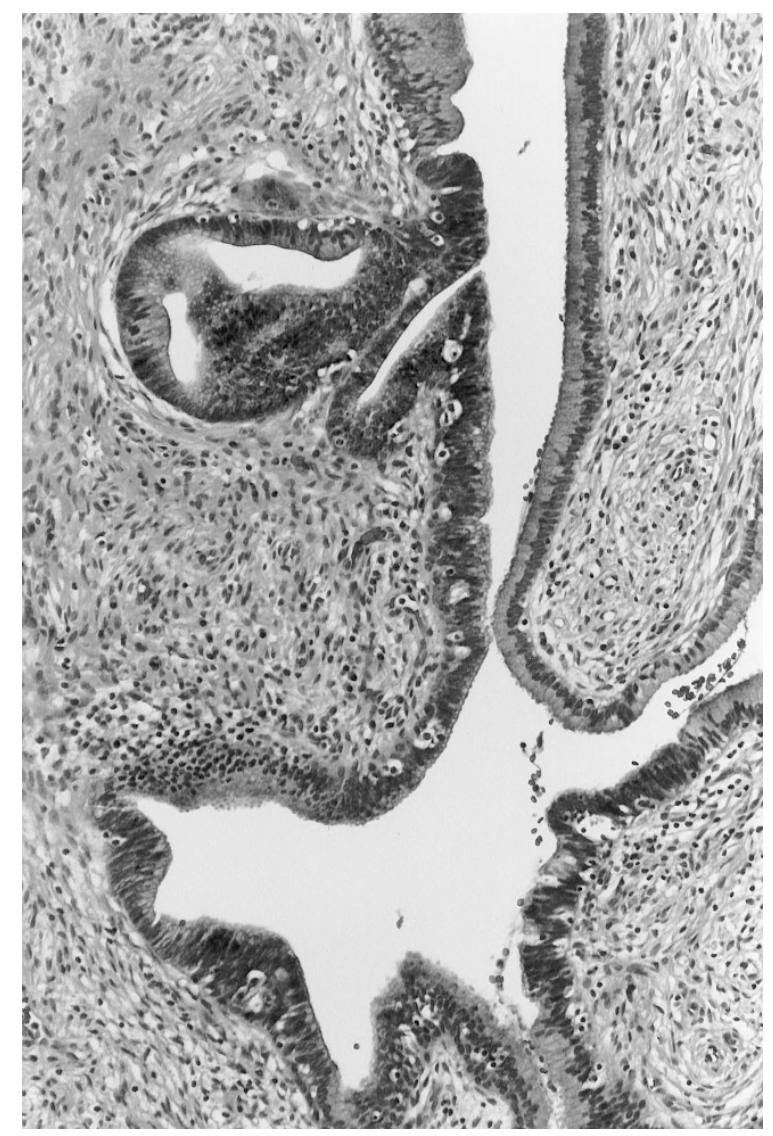

FIGURE 1. Endometrioid adenocarcinoma in situ. Adenocarcinoma in situ of the endocervix generally is characterized at low magnification by the preservation of normal glandular architecture, with an abrupt transition between normal and cytologically atypical cells.
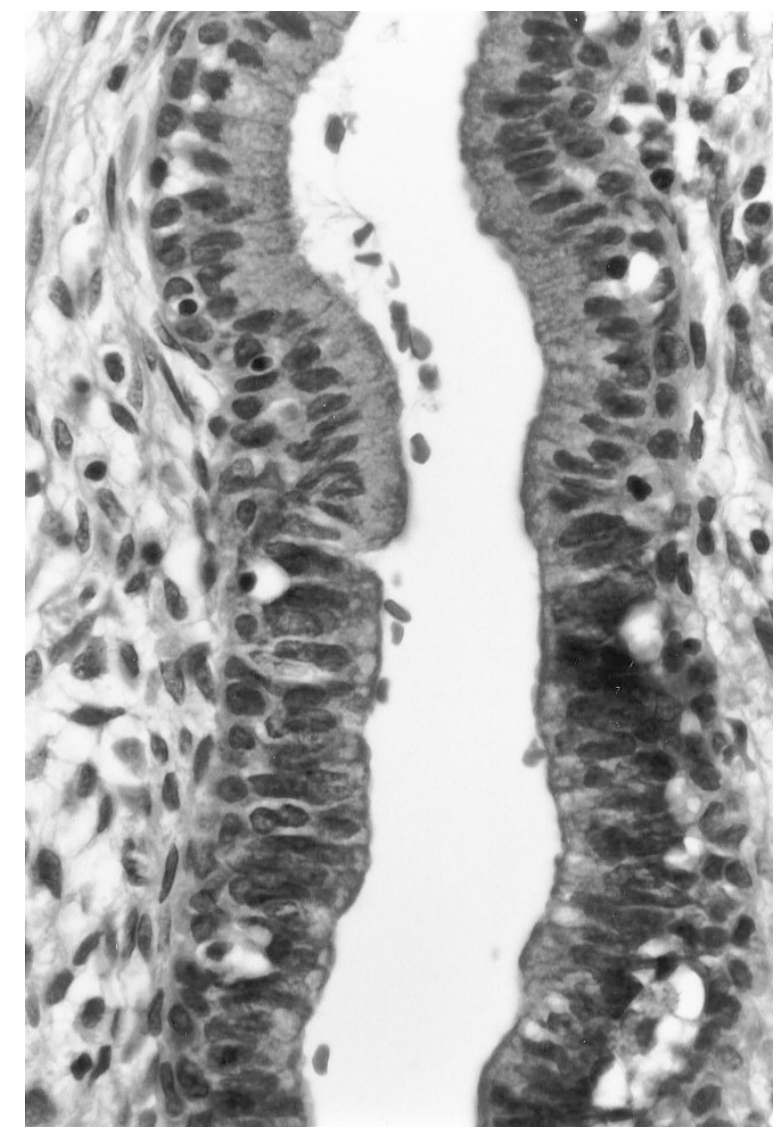

FIGURE 2. Endometrioid adenocarcinoma in situ. At higher magnification, the features of adenocarcinoma in situ are evident, including nuclear enlargement, coarse chromatin, and stratification of nuclei.

those with invasive adenocarcinoma; (2) AIS is frequently found adjacent to invasive adenocarcinoma; (3) similar human papillomavirus (HPV) types are found in both AIS and invasive adenocarcinoma; and occasionally (4) invasive adenocarcinoma has occurred after AIS was discovered but untreated.

A variety of subtypes of AIS have been described based on cytoplasmic characteristics, including (1) endocervical, (2) intestinal, (3) endometroid, and (4) mixed adenosquamous types. The endocervical type retains a basic resemblance to the normal endocervix, with at least focally vacuolated, often granular, pale, basophilic to eosinophilic cytoplasm (Fig. 3). The intestinal type displays distention of apical cytoplasm by a large mass of mucin, resembling intestinal goblet cells (Fig. 4). The endometrioid type is characterized by cells with densely eosinophilic cytoplasm containing no apparent mucin in routinely stained sections, resembling hyperplastic glands of the endometrium (Fig. 2). Adenosquamous carcinoma in situ may be either composed of a mixture of cells of squamous and glandular types or formed of a uniform population of cells with characteristics intermediate in appearance between glandular and squamous cells, with eosinophilic cytoplasm of polyhedral shape (Fig. 5). 


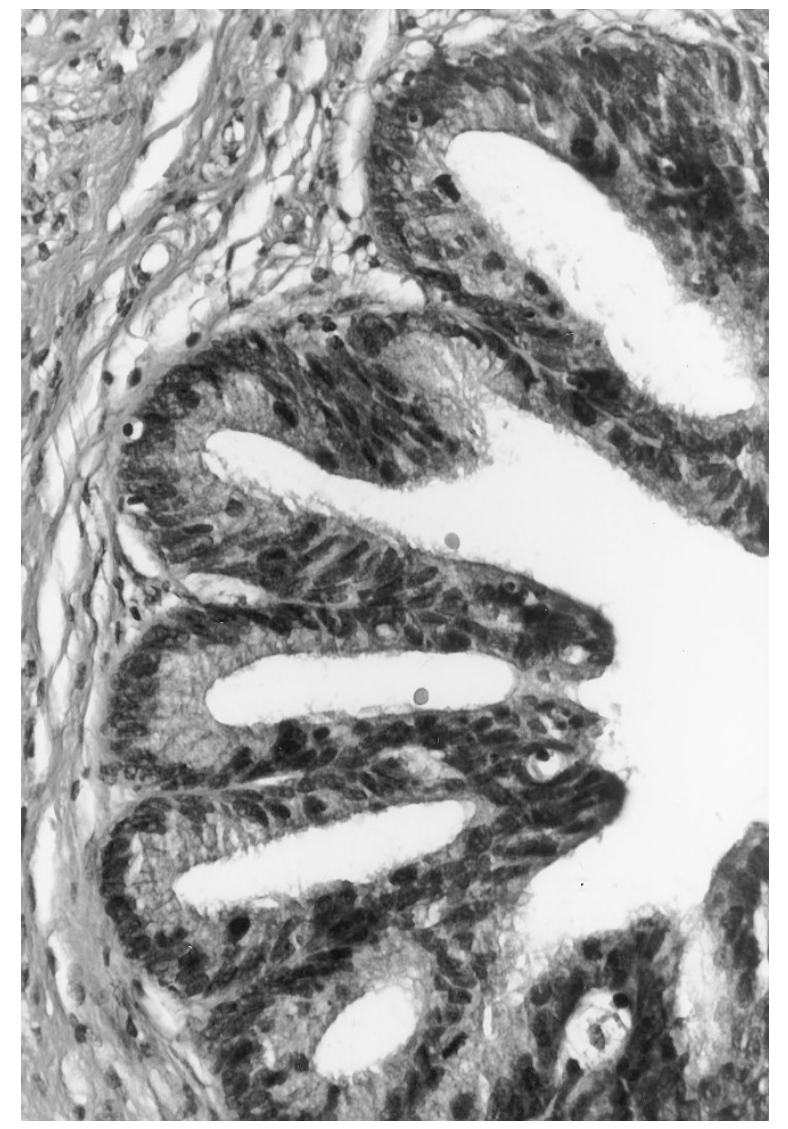

FIGURE 3. Endocervical adenocarcinoma in situ (AIS). In addition to the features of AIS, the retention of mucin vacuoles as fine vacuoles in the cytoplasm defines this as the endocervical type of AIS.

These lesions should be distinguished from AIS that is simply coexistent with but physically separate from a squamous dysplasia.

Although no biologic significance has yet been linked to the different cell types, their subdivision is justified in simply aiding the pathologist to recognize them as AIS.

Although immunohistochemistry has been of limited assistance in distinguishing reactive from malignant glandular cells of the cervix, the recent description of $\mathrm{MN}$ protein expression in malignant glandular lesions suggests the potential to discriminate on this basis (5).

\section{Glandular Dysplasia}

Glandular dysplasia (or atypical hyperplasia) has been proposed as a pathologic entity on the basis of the assumption that glandular lesions progress through a series of lesions of distinctive morphology as they acquire the genetic and phenotypic changes of carcinomas similar to squamous lesions of the cervix. This theoretical concept is supported by the observation of significant heterogeneity in the manifestation of atypia in cervical biopsies in the absence of obvious inflammatory changes.

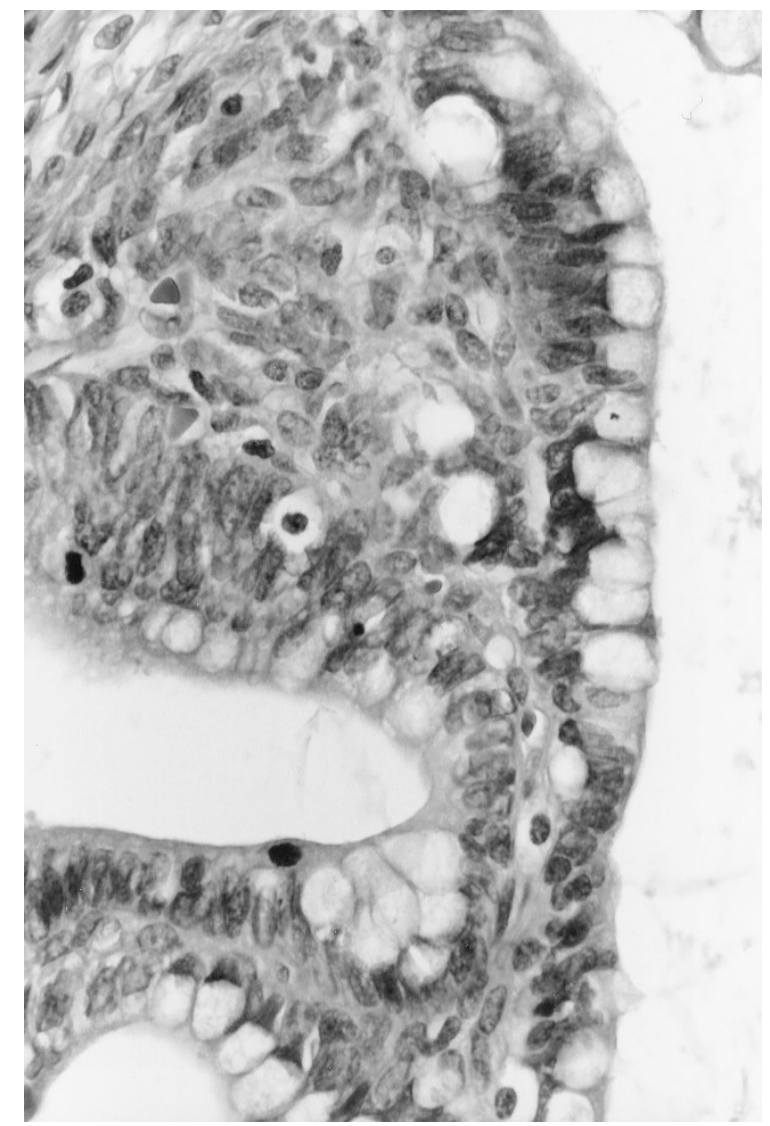

FIGURE 4. Intestinal adenocarcinoma in situ. The presence of large mucin vacuoles that distend the cytoplasm to form goblet cells characterizes the intestinal type of endocervical adenocarcinoma in situ.

There is no shortage of proposed definitions for glandular dysplasia:

1. Glands that are lined by cells with slightly atypical nuclei that are not fully malignant, and with fewer mitoses than AIS (1)

2. The presence of only one gland with histologic features of AIS

3. Nuclear atypia and evidence of cell turnover (apoptotic bodies) and two or fewer mitoses per gland (6)

4. Nuclear enlargement, hyperchromasia, stratification, pleomorphism, abnormal chromatin, increased mitoses, mucin depletion, and abnormal gland architecture (7)

5. Moderate nuclear enlargement, hyperchromasia, atypia, with fewer mitoses than AIS (8)

Brown and Wells (9) in 1986 further distinguished low-grade from high-grade dysplasia on the basis of the paucity of mitoses, absence of vesicular chromatin, and restriction of stratification of nuclei to the basal two thirds of the epithelium in low-grade lesions. However, until diagnostic reproducibility was established and biologic correlates had been elucidated, they suggested that the whole spectrum of histologic changes including AIS be regarded as a 


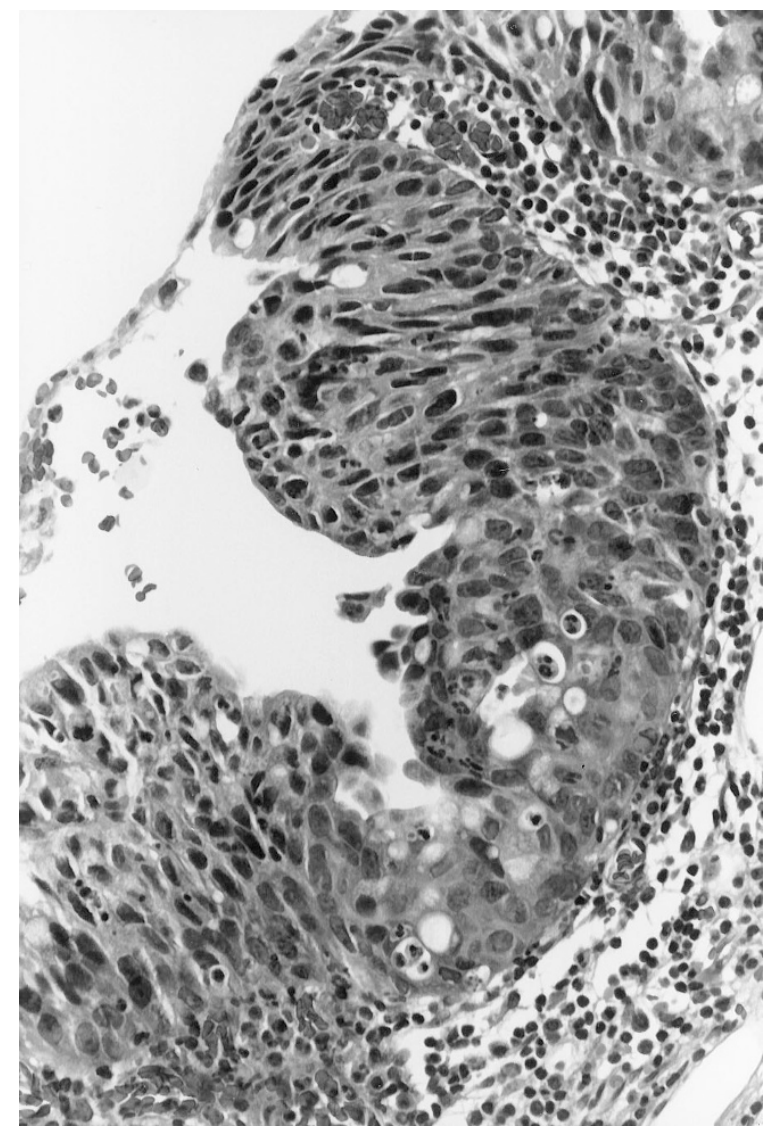

FIGURE 5. Adenosquamous carcinoma in situ. A mixture of cells with cytologically atypical nuclei and either squamous or glandular differentiation of the cytoplasm is present. The squamous differentiation is recognized by dense eosinophilic cytoplasm, whereas glandular differentiation is manifest as large mucin vacuoles.

single lesion. Gloor and Hurlimann (10) in the same year divided dysplasia into three grades on the basis of almost identical criteria. Some of the lesions classified as low-grade dysplasia seem to represent reactive or metaplastic changes, whereas those of high grade are indistinguishable from AIS to me. The heterogeneity in the histologic appearance of precursor lesions may also reflect the differences in the expression of cytoplasmic differentiation in the various subtypes of AIS, as described previously. Although it is reasonable to attempt to make the distinction of dysplasia from AIS in the setting of research investigating the pathogenesis of adenocarcinoma, I suggest that we not use the term glandular dysplasia as a diagnosis, because it will almost certainly prompt a call from a clinical colleague who would like to discuss its behavior and appropriate therapy-for which we have no answers. Glandular dysplasia may exist, but I believe that no one knows what it is biologically or how to recognize it in a reproducible fashion.

Irrespective of the number of cells or glands involved, lesions that contain columnar cells with enlarged nuclei, coarse chromatin, increased nuclear:cytoplasmic ratios, and mitotic activity are probably best classified and treated as AIS.

\section{DISTINCTION OF INVASIVE FROM PREINVASIVE ADENOCARCINOMA IN THE ENDOCERVIX}

There are two unequivocal features that identify the presence of invasion in endocervical adenocarcinoma (Fig. 6): (1) individual cells or incomplete glands lined by cytologically malignant-appearing cells at a stromal interface and (2) malignantappearing glands surrounded by a desmoplastic host response.

It is critical first to ascertain that the glands are lined by cytologically malignant-appearing cells, because endocervicitis, microglandular hyperplasia, and rupture of mucin-filled glands all may have incomplete glands that at times may be associated with a host response of dense inflammation and, occasionally, edema or fibrosis.

Unfortunately, many adenocarcinomas do not display these two changes yet are invasive. Three additional features that are not entirely specific may help to identify invasion in other cases: (1) ar-

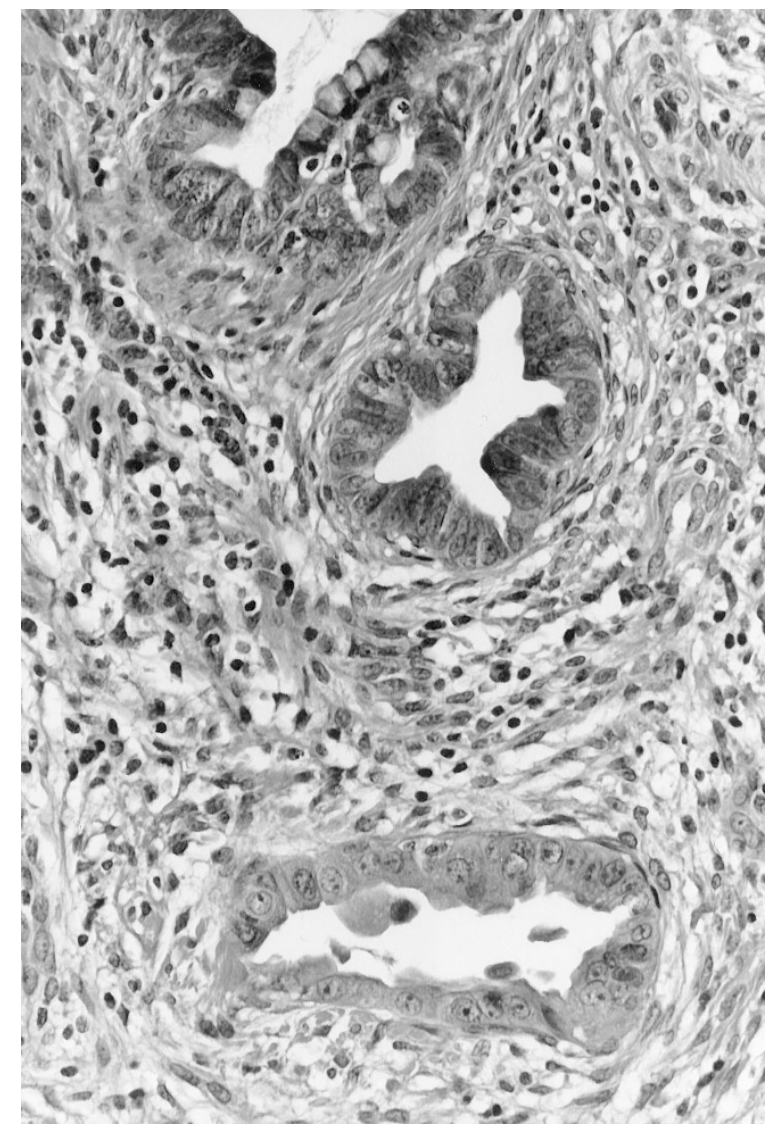

FIGURE 6. Early invasive adenocarcinoma. Invasion can be unequivocally recognized by the presence of a malignant-appearing gland (bottom) surrounded by a desmoplastic host response. Adenocarcinoma in situ involving two glands is evident more superficially. 
chitecturally complex, branching, or small glands, which grow confluently or in a labyrinthine pattern (Fig. 7); (2) a cribriform growth pattern of malignant-appearing epithelium devoid of stroma within a single gland profile; and (3) the presence of glands below the deep margin of normal glands.

Large masses of densely packed architecturally complex glands with luminal bridges and a cribriform growth pattern strongly suggest invasion. More difficult is the assessment of the "deep margin" of normal glands. Although it is stated that endocervical glands should be confined to the inner third of the cervix and less than $1 \mathrm{~cm}$ deep, benign glands in various patterns including Nabothian cysts, tunnel clusters, laminar endocervical hyperplasia, deep endocervical glands, and mesonephric duct remnants may be found deeper in the stroma on occasion (11).

\section{DEFINITION AND SIGNIFICANCE OF MICROINVASIVE ADENOCARCINOMA}

The basement membrane first traversed by invading cells of cervical adenocarcinoma is often not that of the surface epithelium and may be any-

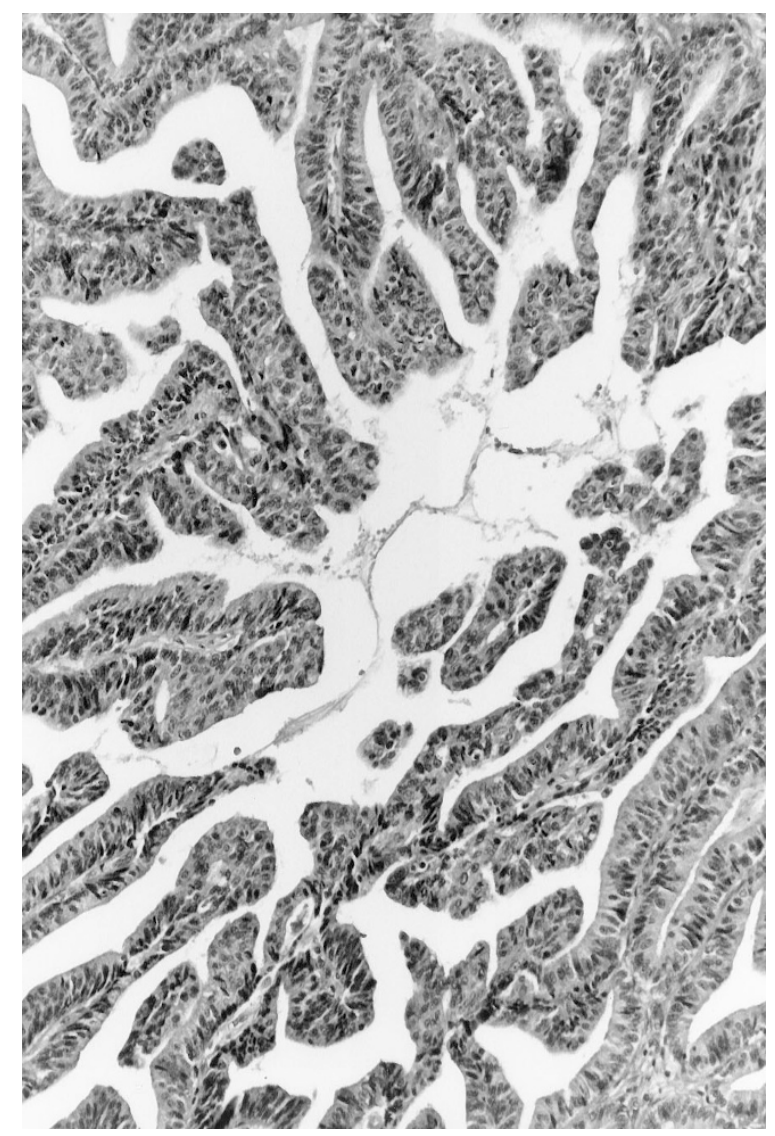

FIGURE 7. Probable early invasive adenocarcinoma. A complex maze or labyrinthine pattern has been suggested as a feature to assist in the recognition of early invasion by adenocarcinoma of the endocervix. This feature has not been validated as pathognomonic for invasion. where along the profile of a gland. Given the architectural complexity of the endocervical glands that are formed by a deeply invaginated epithelium with secondary branching and tunnel formation (12), the accurate measurement of depth of invasion is always problematic in early endocervical adenocarcinomas.

As concluded by Clement and Young (13) and Yeh et al. (14), there is no consensus regarding the criteria for the diagnosis of microinvasive adenocarcinoma (MIA) of the cervix. Qizilbash (4) in 1975 described three patterns of MIA: glandular budding with an associated inflammatory reaction, confluent glands in a complex pattern with little or no intervening stroma, and intraluminal tufting resulting in a papillary pattern. All of the lesions had to be less than $5 \mathrm{~mm}$ thick. Subsequent authors generally have chosen a similar definition that restricts cases of MIA invasion to less than $5 \mathrm{~mm}$ from the basement membrane of the surface epithelium $(3,15)$, although Fu and Reagan (16) confined MIA to tumors with less than $1 \mathrm{~mm}$ invasion and the absence of confluent glands. Burghardt (17) suggested that microcarcinomas be of less than $500 \mathrm{~mm}^{3}$. Gompel and Silverberg (8) further restricted the use of the term to tumors that are so small as not to be measurable. As Buscema and Woodruff (18) appropriately pointed out, invasion with adenocarcinoma, unlike squamous carcinoma, usually is not a singlecell event but involves the entire gland and that measurement of the depth of invasion is a tenuous assessment because the glands normally are surrounded by stroma.

In a study of 49 women with MIA in whom invasion was limited to $5 \mathrm{~mm}$ from the surface basement membrane, Ostor et al. (19) found no evidence of parametrial, adnexal, or nodal disease. However, occasionally women with apparently superficial cervical adenocarcinomas have metastatic spread. Although Berek et al. (20) found no metastasis in the 6 women with tumors of less than $2 \mathrm{~mm}$, 2 of 18 with 2- to 5 -mm stromal invasion had metastatic adenocarcinoma to the pelvic nodes. Teshima et al. (21) followed 22 women with MIA and identified one pelvic recurrence in a woman who had a tumor with $3 \mathrm{~mm}$ of stromal invasion. Kaspar et al. (22) found that a tumor volume of more than $500 \mathrm{~mm}^{3}$ was a better predictor of pelvic lymph node metastasis than depth of stromal invasion in early cervical adenocarcinoma.

The relatively scant data suggest that there is a biologic continuum for adenocarcinoma of the cervix with an increasing probability of metastasis accompanying an increasing depth or quantity of stromal invasion. I think the patient is better served by providing the measurement (i.e., best guess) of stromal invasion rather than by attaching a poorly defined term such as microinvasive carcinoma, 
which may provide a false sense of security to a patient and her physician.

\section{EPIDEMIOLOGY AND PATHOGENESIS OF CERVICAL ADENOCARCINOMA}

An absolute as well as a relative increase in the incidence of adenocarcinoma of the cervix has occurred in the United States during the past 20 years (23-25). The relative frequency of adenocarcinoma is now approximately 15 to $20 \%$ of all invasive cervical carcinomas. Among a variety of other factors investigated $(26,27)$, including the absence of a prior Pap smear, number of sexual partners, age at first intercourse, history of genital infections, obesity, and tobacco use, two conditions have emerged as potential risk factors in the development of cervical adenocarcinoma: HPV infection and oral contraceptive (OCP) use.

Although morphologic evidence of productive HPV infection generally is limited to squamous or transitional epithelium, an overwhelming body of data now supports the extremely high frequency of HPV infection in both AIS and invasive adenocarcinoma (28-33). Wart viruses were not found in many of the in situ and invasive adenocarcinomas of the cervix studied in the early 1980s, but with more sensitive techniques, HPV 16, 31, and, more frequently, 18 have been identified in adenocarcinomas and adenosquamous carcinomas with a frequency of $80 \%$ or more. The linkage of HPV infection to causality of adenocarcinoma is as strong as it is for squamous carcinoma of the cervix, although the reason for preferential infection by HPV 18 remains unclear.

More controversial are the data surrounding the relationship between hormone use and cervical adenocarcinoma (34). The introduction of OCPs in the 1960s was followed a decade later by the recognition of an atypical proliferative lesion, microglandular hyperplasia, in young women using these agents. It is not surprising that the similar temporal association between OCP introduction and the increased incidence of cervical adenocarcinoma has suggested the possibility of a causal relationship. In 1983, Vessey et al. (35) identified an increase in dysplasia, carcinoma in situ, and invasive carcinoma of the cervix among women who used an OCP compared with those who used an intrauterine device. Shortly thereafter, Dallenbach-Hellweg (36) noted a 2-fold increase in the frequency of OCP use among young women with adenocarcinoma of the cervix compared with those with squamous carcinoma. Subsequent larger epidemiologic studies generally but not uniformly have demonstrated a 1.5- to 5-fold increase in the odds ratio for prior use of OCPs among women with cervical adenocarci- noma compared with controls $(27,37-39)$. However, these studies have not adjusted for HPV infection status.

Preliminary results from a yet unpublished casecontrol study from the National Cancer Institute demonstrate a strong relationship between adenocarcinoma and infection with HPV types 18 and 16 but no relationship to parity or cigarette smoking. The prior use of OCPs was associated with cervical adenocarcinoma, but this association was diminished when adjusted for HPV infection and was confined primarily to AIS and not invasive adenocarcinoma. In summary, the epidemiology and pathogenesis of cervical adenocarcinoma appear similar but not identical to those of squamous carcinoma, with an intriguing but still unproved relationship with OCP use.

\section{HISTOLOGIC TYPES OF INVASIVE ADENOCARCINOMA}

Although the prototypical endocervical adenocarcinoma retains a resemblance to the Müllerian mucinous epithelium, the pathologist needs to be aware of the disparate morphology displayed by carcinomas that arise in the endocervix, some of which are associated with a distinctive biologic behavior. Although older studies suggested that the prognosis for typical adenocarcinomas was worse than that for squamous cervical cancer, more recent studies that adjusted for depth, stage, and therapy generally have not identified a significant difference $(23,40)$.

\section{Mucinous Adenocarcinoma}

Three types of mucinous adenocarcinoma occur in the cervix, the most common of which is the endocervical type, which resembles the cells lining the endocervical glands. The neoplastic counterpart is formed of cells arranged in glands that may be simple or branching, tubular or papillary, with basal or stratified nuclei, and pale granular to vacuolated cytoplasm that stains for mucins. The intestinal type mimics the colonic epithelium and is characterized by glands that are lined by malignant-appearing cells, some of which have their cytoplasm distended by a single large vacuole of mucin, forming a goblet cell. Signet-ring cell carcinomas may be pure or mixed with either of the other two mucinous types and contain single cells or solid aggregates of polygonal cells with a nucleus displaced eccentrically by mucinous vacuoles.

\section{Endometrioid Carcinoma}

Endometrioid carcinoma may actually be more common than the endocervical type and histologi- 
cally is indistinguishable from its counterpart in the uterine corpus. No mucin vacuoles are identifiable in hematoxylin and eosin-stained sections. The presence of vimentin in the neoplastic cells of more than $80 \%$ of endometrioid carcinomas of the endometrium helps to distinguish them from endometrioid carcinomas of the endocervix, only approximately $13 \%$ of which contain vimentin (41). The distinction is important because the therapy and prognosis differ based on the site of origin.

\section{Clear Cell Carcinoma}

During the past 30 years, most of the clear cell carcinomas of the endocervix have been in young women exposed to diethylstilbestrol in utero. The withdrawal of diethylstilbestrol from the commercial market more than 25 years ago is now resulting in a reduction in these tumors and redistribution, with the preponderance of new cases occurring in older women. The patterns include tubulocystic, papillary, and solid, formed of cells with either clear or eosinophilic cytoplasm.

\section{Villoglandular Carcinoma}

Young and Scully (42) presented the clinicopathologic features of villoglandular carcinoma of the cervix in 13 patients in 1989. Often occurring in women who are younger than 40 years, these tumors are characterized by surface papillae that vary from long, delicate, fingerlike projections to short, broad, complex, and branching with variable amounts of stroma (Figs. 8, 9). The superficial parts of the tumors often resemble villous adenomas, whereas deeper portions of the tumor are often formed of branching glands. Nuclear pleomorphism and mitotic activity are mild or moderate, mucin is variable, and a desmoplastic host response is often absent. Because of the modest atypicality and absence of desmoplasia, the diagnosis of carcinoma is often challenging. Invasion usually cannot be assessed in an initial, superficial biopsy, and cone biopsy or hysterectomy is necessary for definitive evaluation. Although stromal invasion was identified in 8 of 13 cases, no deaths from tumor were described in this or another study of an additional 24 patients (43). However, occasional cases display a conventional cribriform or glandular pattern confined to the deep stromal interface, and four cases with greater cytologic atypia and nodal spread have been reported $(13,44,45)$, emphasizing the importance of a complete histologic examination.

\section{Minimal Deviation Adenocarcinoma}

Alternatively called adenoma malignum or extremely well-differentiated adenocarcinoma, the

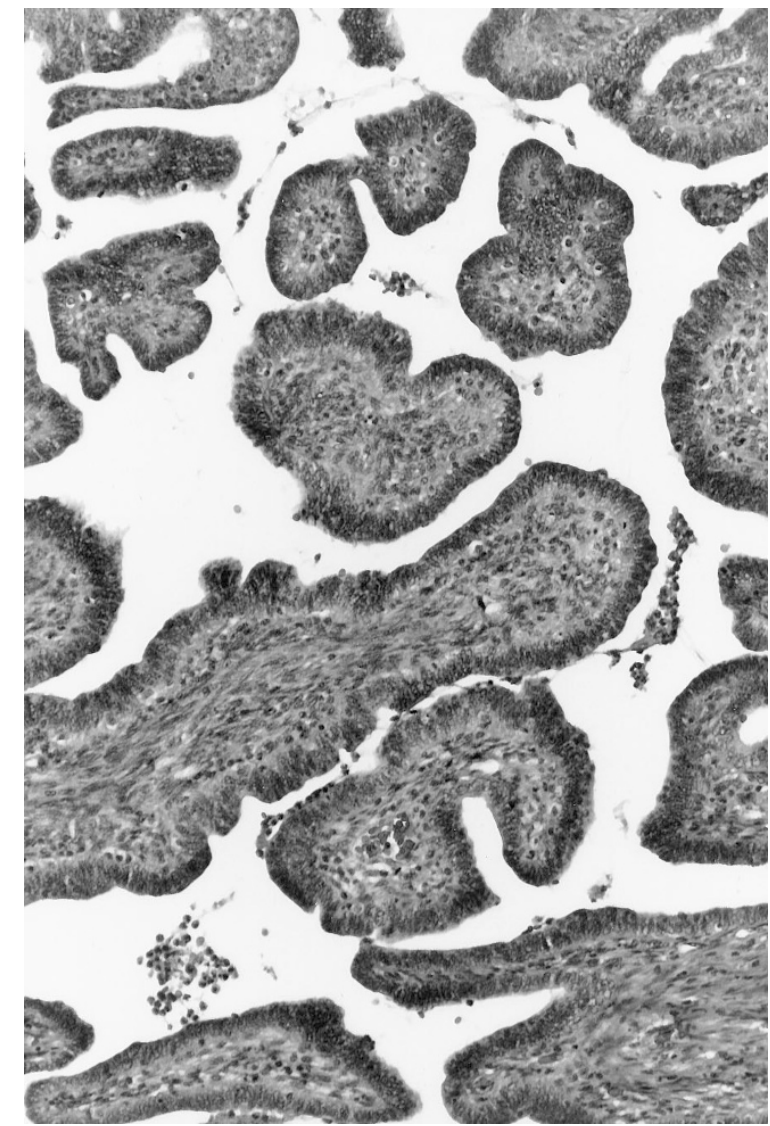

FIGURE 8. Villoglandular adenocarcinoma. The superficial portion of this tumor is formed of broad papillae, with fibrovascular cores covered by a mildly atypical stratified columnar epithelium. No tissue invasion is evident in this section.

term minimal deviation adenocarcinoma (MDA) reflects a bland histologic appearance that belies the fully malignant biologic potential (46-49). The tumors are often diagnosed in the early fifth decade, and a minority are a component of the PeutzJeghers syndrome. Grossly, the cervix is often firm or indurated. Histologic features include glands lined by columnar cells with mucinous apical cytoplasm and basal nuclei of generally bland cytology. Helpful features in arriving at the correct diagnosis include (1) variability in gland shape and size, often with large size with branching, cystic dilation, or papillary enfolding of the epithelium; (2) the presence of a desmoplastic host response; (3) an irregular, angulated gland contour; and (4) at least rare mitotic figures. Areas of malignant cytology, vascular invasion, or perineural invasion confirm the diagnosis and are present in approximately half of cases. Stromal invasion deeper than normal glands is common but not helpful in superficial biopsies. The small number of cases of MDA and generally deep invasion at diagnosis make characterization of behavior somewhat unreliable, but the majority of women have had nodal spread and ultimately died of tumor. Benign lesions that must be distinguished from MDA include tunnel clusters, deep Nabothian 


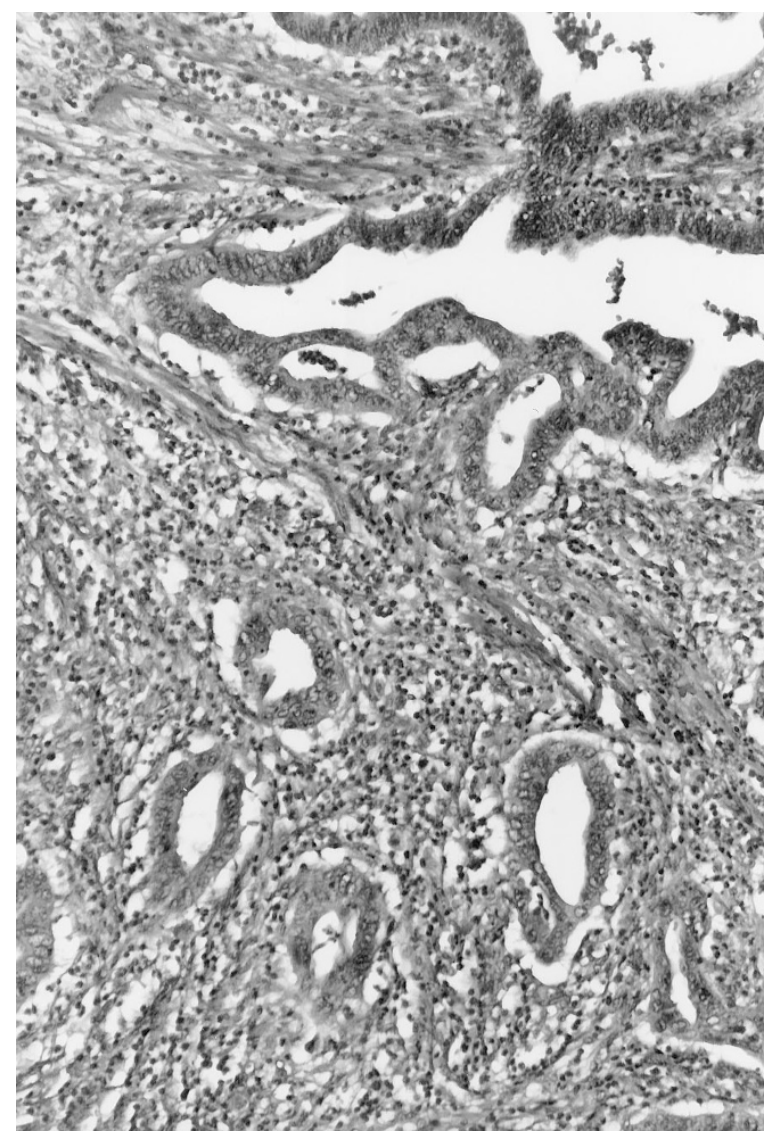

FIGURE 9. Villoglandular adenocarcinoma. At the base of the lesion depicted in Figure 8, a conventional pattern of invasive endocervical adenocarcinoma with a higher degree of cytologic atypia is present at the stromal interface. The behavior of such tumors may be more aggressive than that of tumors of pure villoglandular differentiation.

cysts, and diffuse laminar endocervical glandular hyperplasia (see below). Minimal deviation endometrioid adenocarcinomas composed of small, uniform glands with no host response have also been described and seem to have a much better prognosis $(47,50)$ (Fig. 10).

\section{Serous Carcinoma}

Identical histologically to its counterpart in the endometrium or ovary, serous carcinoma is rare in the cervix (51) and is composed of papillae or branching, gaping glands lined by cells with pleomorphic nuclei and often centrally protruding apical cell cytoplasm, resulting in a scalloped configuration. A recent study (52) of 17 cases of serous carcinoma identified a survival rate similar to that of conventional adenocarcinoma of the cervix. Probably equally important was the discovery of coexisting villoglandular adenocarcinoma in five cases, again stressing the need for careful examination of tumors that look like villoglandular adenocarcinoma.

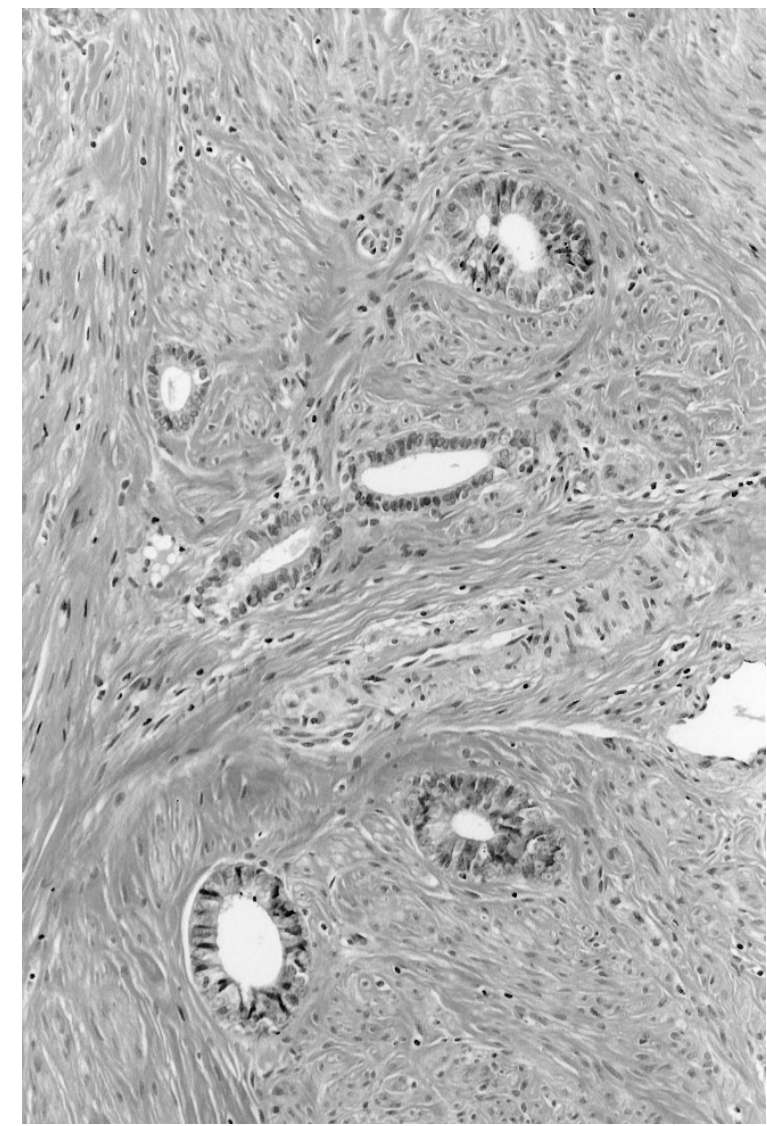

FIGURE 10. Minimal deviation adenocarcinoma. In the endometrioid type of minimal deviation adenocarcinoma, small uniform glands lined by relatively bland non-mucin-secreting cells are scattered deep in a stroma that lacks any desmoplastic response. This lesion may be impossible to diagnose in a superficial biopsy.

\section{Mesonephric Adenocarcinoma}

Mesonephric duct remnants commonly persist along the lateral (and occasionally the anterior or posterior) aspects of the cervix embedded within the fibromuscular stroma. Very rarely, adenocarcinomas arise in these remnants (53-55) and generally are characterized by (1) a location deep in the stroma usually not reaching the endocervical mucosa, (2) arrangement as small glands or tubules, which are (3) lined by cuboidal to low columnar cells with cytologically malignant nuclei devoid of intracytoplasmic mucin, and (4) often associated with benign or hyperplastic mesonephric duct remnants. The behavior usually is aggressive.

\section{Adenoid Basal Cell Carcinoma}

This unusual tumor is often found in asymptomatic menopausal women during the evaluation of an abnormal cervicovaginal cytology $(56,57)$. The cervix rarely is enlarged, and a mass is not commonly evident on pelvic examination. The tumor is characterized by an arrangement of small nests with peripheral palisading of cells similar to that of basal cell carcinoma. An acinar arrangement with a 
central small lumen containing mucin or squamous differentiation in the central portions of the nests is common. However, a desmoplastic host response is rare. The neoplastic cells are small, with oval, hyperchromatic nuclei, inconspicuous nucleoli, rare mitoses, and scant cytoplasm. Foci of squamous differentiation are more common in the superficial nests of tumor, often subjacent to areas of surface squamous dysplasia. Rarely, adenoid basal cell carcinoma may be associated with an invasive conventional squamous cell carcinoma. The prognosis generally is excellent after hysterectomy, although a few cases with lymph node metastases have been reported.

\section{BENIGN LESIONS THAT MIMIC ADENOCARCINOMA}

Making the distinction between some of the benign proliferative lesions and well-differentiated forms of endocervical adenocarcinoma can be very difficult. Immunohistochemistry is of limited assistance, because there are no entirely specific or sensitive reactions that are limited to adenocarcinomas. Nevertheless, well-differentiated adenocarcinomas often display diffusely or at least focally a positive reaction in the cytoplasm for carcinoembryonic antigen (CEA), whereas most of the benign conditions fail to contain CEA. The combination of endocervical glandular cytoplasmic CEA positivity and a moderate to high Ki-67 proliferative index has been suggested as being highly predictive of adenocarcinoma in the endocervix (58). $\mathrm{MN}$ antigen expression reportedly is confined to the cervix of women with dysplasia or carcinoma, but it may be found in histologically benign glands of these cases as well (5). Ultimately, the diagnosis rests on histologic characteristics present in routinely stained sections.

\section{Glandular Atypia}

This very common category, including atypia as a result of inflammation, tissue repair, and response to irradiation, may mimic adenocarcinoma. Inflammation and tissue repair may result in lacelike masses of glandular cells with enlarged, pleomorphic nuclei and prominent nucleoli (Fig. 11). The presence of a dense inflammatory infiltrate, frequently extending into the epithelium, often coupled with loss of polarity and acquisition of abundant, polygonal cytoplasm, assists in the recognition of the presence as reactive. Isolated multinucleated endocervical cells are common. Papillary endocervicitis is a specific form of tissue response characterized by relatively short edematous papillae, often containing lymphoid aggregates, covered by a simple columnar epithelium displaying nuclear changes of reactive cells. In con-

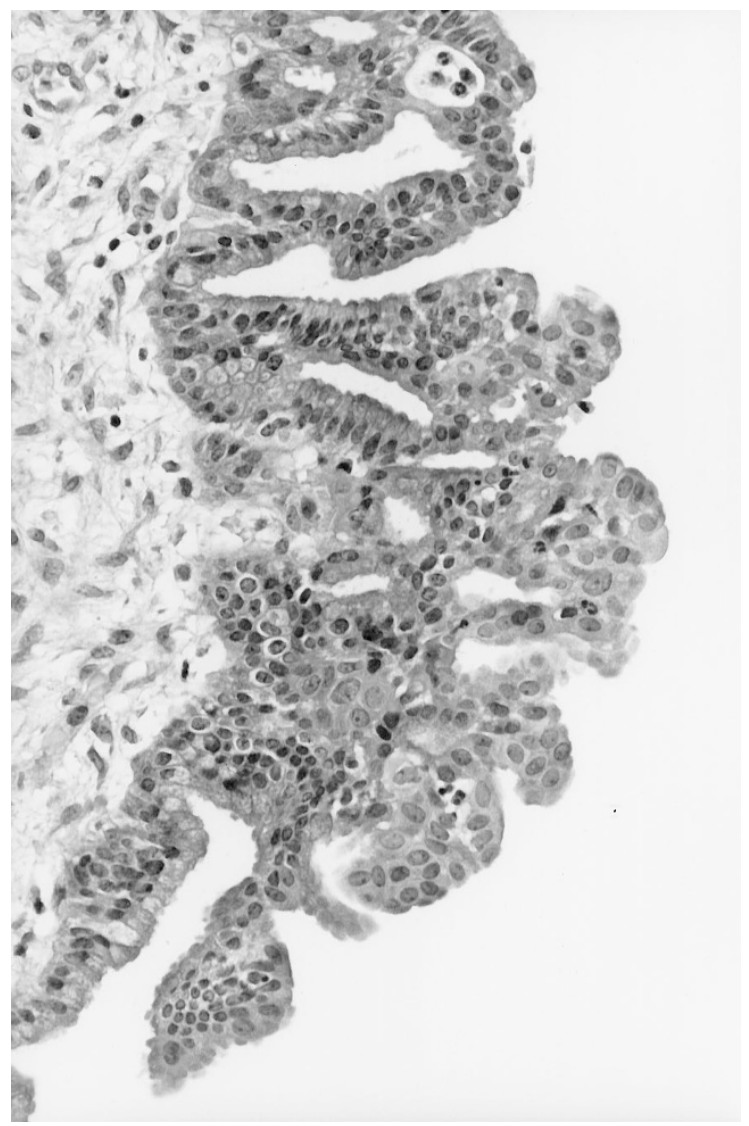

FIGURE 11. Reactive glandular atypia. Lacelike masses of glandular cells, with moderately enlarged nuclei, may occur as a manifestation of tissue repair, sometimes after cone biopsy of the cervix.

trast, radiation may result in glands being lined by large columnar or cuboidal cells with very large, hyperchromatic nuclei, but the chromatin is usually smudged and mitoses are rare (Fig. 12).

\section{Tunnel Clusters}

Fluhmann (59) described the normal endocervical architecture of columnar gland cells covering ridges, from the base of which extend blindly ending small tubules or tunnels. At times, these tubules proliferate to form tunnel clusters, which are divided into two types. Type A clusters are relatively inconspicuous aggregates of tubules that otherwise resemble the mucosal folds cut in various planes. Type B tunnel clusters are often problematic, formed of dilated or cystic tubules arranged in lobular units that may be architecturally complex and different from the usual appearance of endocervical glands (Fig. 13). They frequently are multifocal and usually are approximately $2 \mathrm{~mm}$ in diameter, but in aggregate, they may be greater than $4 \mathrm{~cm}$ in length and $1.5 \mathrm{~cm}$ in thickness (60). Usually, the cystic dilation is consequent to obstruction of the cleft of origin, similar to the genesis of Nabothian cysts. The lining cells are cytologically bland, devoid of mitoses, and rich in mucin. The chief diagnostic 


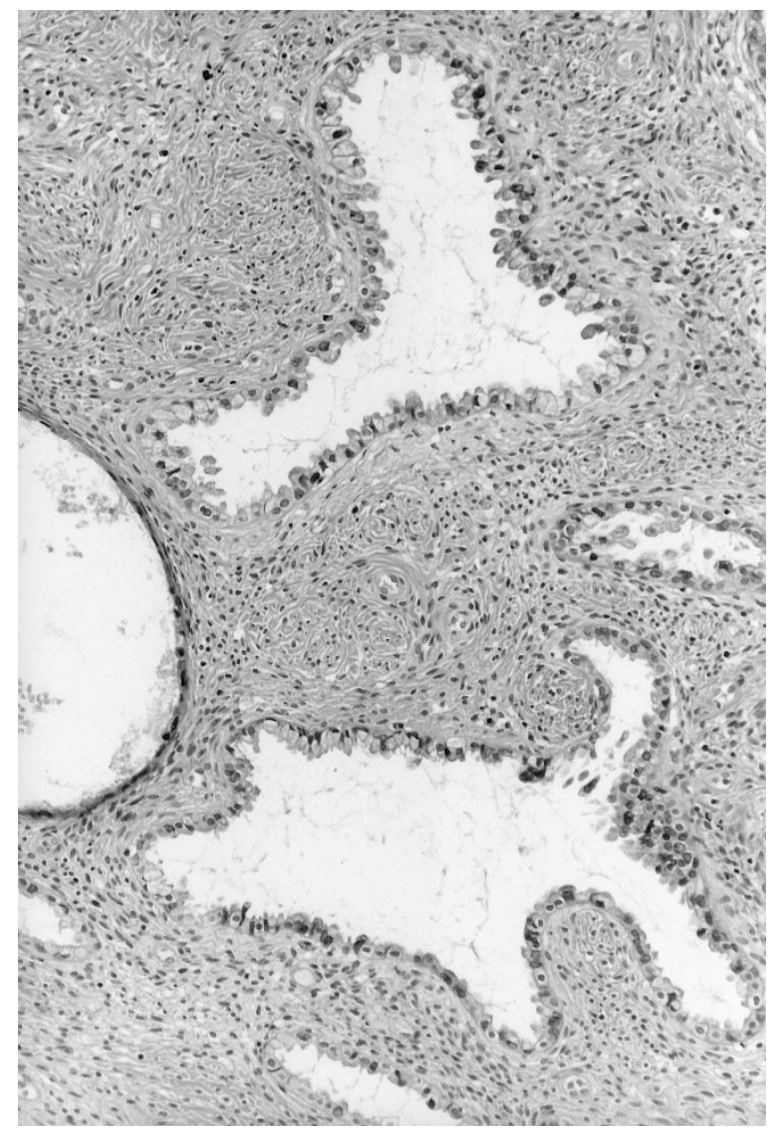

FIGURE 12. Radiation atypia. Radiation causes no architectural changes in glands but pronounced cytologic atypia. The cells lining the glands typically have large hyperchromatic nuclei, with variably sized nucleoli.

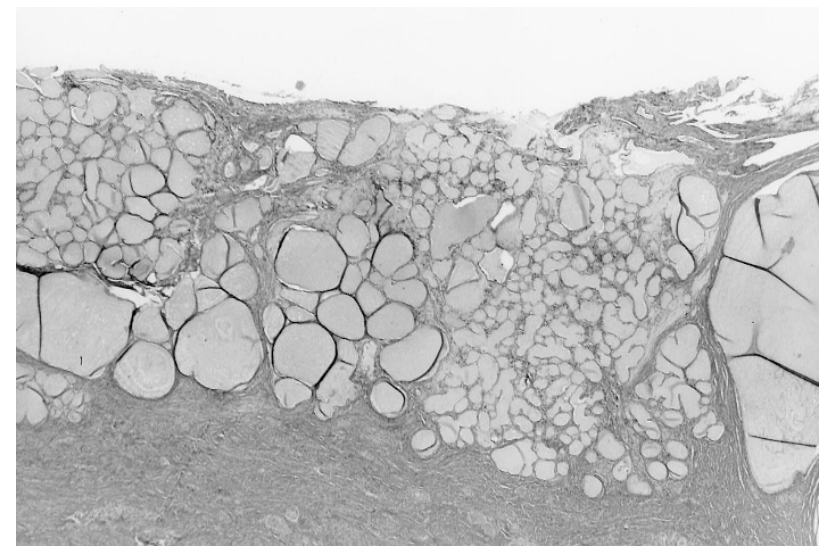

FIGURE 13. Tunnel clusters. The confluence of several type B tunnel clusters may result in a crowded mass composed of several lobular units. The sharp circumscription at the lower stromal interface and bland cytology within flattened cuboidal cells aid in the recognition of the lesion as benign.

concern is its distinction from MDA. The relatively uniform cystic dilation, absence of angulated glands, mitotic activity, or nuclear atypia, coupled with the lobular architectural arrangement, help to confirm the diagnosis of a tunnel cluster.

\section{Deep Glands}

Nabothian cysts occasionally may extend deep into the cervical stroma, exceeding a depth of $1.8 \mathrm{~cm}$ and approaching the paracervical soft tissue or serosa (11). These usually are incidental findings in a hysterectomy specimen and alarm the pathologist by virtue of their depth but not their architectural or cytologic characteristics, which are no different from more superficial Nabothian cysts. Occasional cases of deep endocervical glands, or endocervicosis, result from implantation of benign glands, typically after a Caesarean section. They may be found implanted in the outer third of the stroma or even the paracervical soft tissues. They can be distinguished from MDA by the criteria enumerated previously (see the section "Minimal Deviation Carcinoma”).

\section{Diffuse Laminar Endocervical Glandular Hyperplasia}

Jones et al. (61) described a microscopic proliferation of benign-appearing endocervical glands limited to the inner third of the cervix that may be confused with MDA because of their diffuse distribution. The glands are lined by a single layer of mucin-secreting epithelium with bland, basally oriented nuclei and range from 2 to $9 \mathrm{~mm}$ in depth, with a sharply demarcated deep border. Occasional glands with irregular, angulated contours may be present, and periglandular edema is common, simulating MDA. However, focal cytologic atypia and mitotic activity usually can be found in MDA, and acute or chronic inflammation is frequently associated with the diffuse laminar endocervical glandular hyperplasia.

\section{Microglandular Hyperplasia}

In 1967, Taylor et al. (62) described in 13 young women a peculiar and distinctive form of polypoid hyperplasia of the endocervix that was sufficiently atypical as to raise concern about the possibility of adenocarcinoma. The lesion was found only in women who had been taking OCPs. Shortly thereafter, Kyriakos et al. (63) termed the lesion $m i$ croglandular hyperplasia because of the tightly packed, generally small glands, lined by flattened to cuboidal cells, sometimes arranged in a reticular pattern or as solid cords without a central lumen. Nuclei are often vesicular, nucleoli are indistinct, and mitoses are rare. The cytoplasm is granular, with subnuclear clear vacuoles, resembling endometrial glandular cells in the early secretory phase. The classical forms are now well known to pathologists because the condition is common and not restricted exclusively to women who have been exposed to progestins (64). This lesion may be CEA positive. Atypical forms including solid, hobnail, signet ring, and infiltrative types may merge with more typical areas (65) (Fig. 14). 


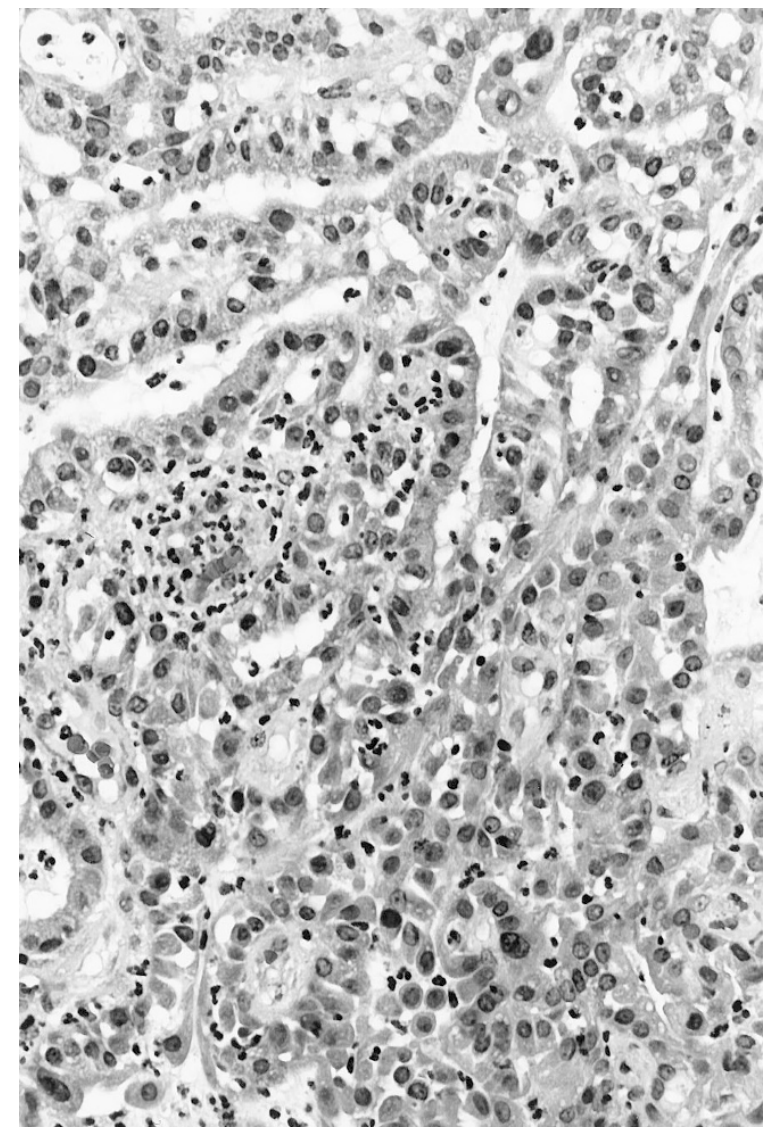

FIGURE 14. Microglandular hyperplasia (MGH). Whereas the classical form is common and well recognized by pathologists, the solid variant may be a source of confusion with clear cell carcinoma. The paucity of mitoses and relatively slight cytologic atypia favor the diagnosis of MGH, and, fortunately, areas of more typical MGH usually coexist with the solid variant.

\section{Mesonephric Hyperplasia}

The mesonephric, or Wolffian, ducts commonly persist as small remnants usually located in the lateral walls of the vagina or cervix, in the broad ligament, and in the hilus of the ovary. Microscopic lobules frequently surround a central duct within the deep cervical stroma. The acini are lined by cuboidal cells with oval, bland nuclei and scant to moderate quantities of eosinophilic cytoplasm. Mucin is not present in the cytoplasm, but a dense, periodic acid-Schiff-positive, luminal secretory product is common. Hyperplasia typically is an incidental finding and is divided into lobular, diffuse, and ductal types $(53,66)$.

The lobular pattern usually is an exaggerated proliferation of the normal, with a diameter varying from 4 to $22 \mathrm{~mm}$ and variability in ductular size and shape without cytologic atypia and with only rare mitoses. It may approach or reach the endocervical mucosa.

The diffuse pattern offers greater diagnostic challenge because in one series, the lesions varied from 13 to $25 \mathrm{~mm}$ in greatest dimensions, extended to the deep edge of the cervix, and were not restricted to the lateral walls (53) (Fig. 15). Occasional foci of gland crowding with angulated gland contours can simulate carcinoma.

Ductal hyperplasia is rare and consists of papillary tufting of the duct epithelium (Fig. 16). The distinction from mesonephric carcinoma is based on the disorderly invasion, back-to-back crowding, and cytologic atypia usually present in carcinoma.

\section{Tubal (Tuboendometrioid) Metaplasia}

Ciliated, non-mucin-secreting columnar cells are a normal component of the endocervical mucosa, most commonly populating part of the upper endocervical canal. Endocervical brushes now facilitate sampling of this region for cytologic examination and have increased the frequency of our encounters with this condition in Pap smears. Tubal metaplasia is defined by the presence of the three types of cells that populate the fallopian tube: ciliated (clear), secretory (nonciliated), and intercalary (peg) cells (67) (Fig. 17). The ciliated cells have large, oval, sometimes hyperchromatic nuclei; variable nucleoli; eosinophilic cytoplasm; and abundant apical cilia. The nonciliated cells often have

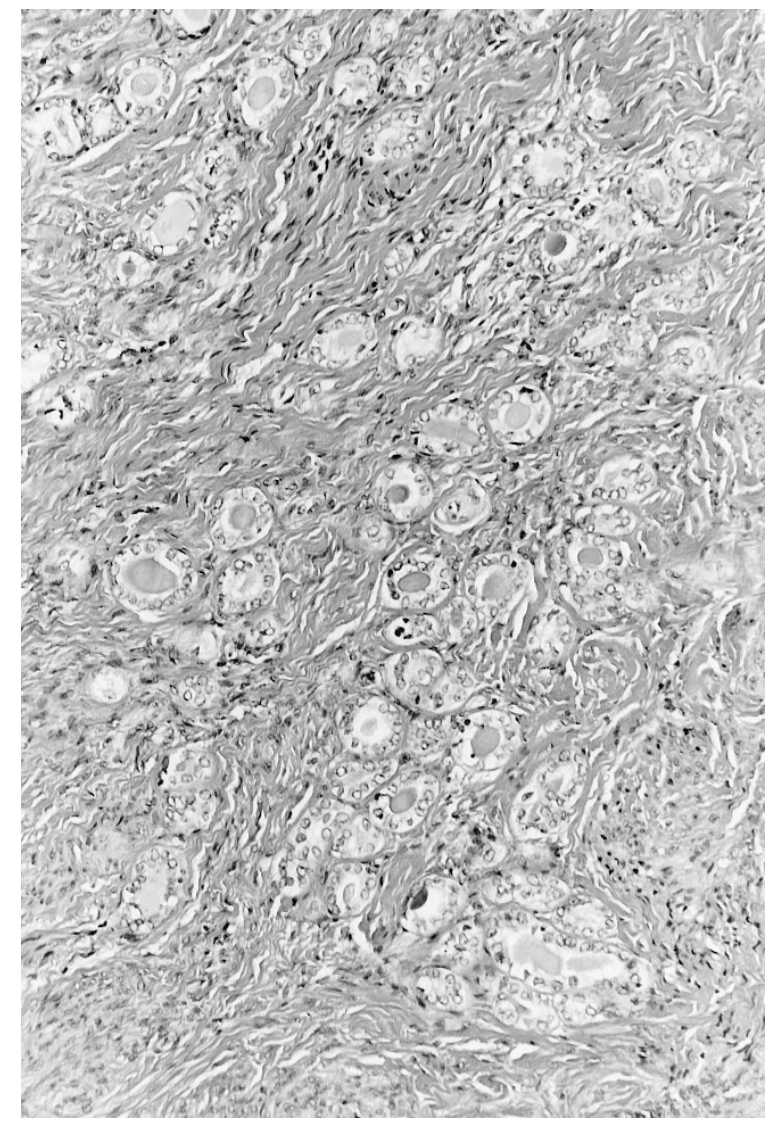

FIGURE 15. Mesonephric hyperplasia. The presence of bland glands deep within the cervical stroma frequently is a source of concern about the possibility of minimal deviation adenocarcinoma. Mesonephric hyperplasia of diffuse type can be recognized as acini lined by cuboidal non-mucin-secreting cells with bland oval nuclei. A dense, periodic acid-Schiff-positive, luminal secretory product typically is present. 
basal nuclei and dark eosinophilic to basophilic cytoplasm, lack mucin vacuoles, and have apical cytoplasmic protrusions. The intercalary cells are probably a variant of nonciliated cells with thin, long nuclei and scant cytoplasm, which seems compressed by adjacent cells. A thorough examination of the cervix has demonstrated the presence of tubal metaplasia in approximately one third of women, evenly distributed among age groups, and most common in the deeper aspect of glands in the upper endocervix (67), although the age and site distribution has been disputed by others (68). Stratification of nuclei, nuclear hyperchromasia, and the presence of nucleoli may suggest AIS, but the numerous cilia and paucity of mitoses help define the lesion as metaplastic. A lower proliferation index has been identified in most cases of tubal metaplasia compared with AIS (69). Variants with deep and irregular glands or periglandular stromal alterations have also been described (70).

Schlesinger and Silverberg (71) recently reported on an abnormality with which we all struggleglands formed of ciliated cells with highly atypical and pleomorphic nuclei. They suggested that this might represent a subtype of AIS. The distinction of "atypical tubal metaplasia" from the proposed lesion referred to as glandular dysplasia remains unclear.

\section{Arias-Stella Reaction}

This change has been observed in the cervix of approximately $10 \%$ of gravid hysterectomy specimens, typically is focal, and histologically is identical to the Arias-Stella reaction in the endometrium (13). The glands are lined by polyhedral cells with large, hyperchromatic nuclei and abundant cytoplasm, which either is eosinophilic or contains

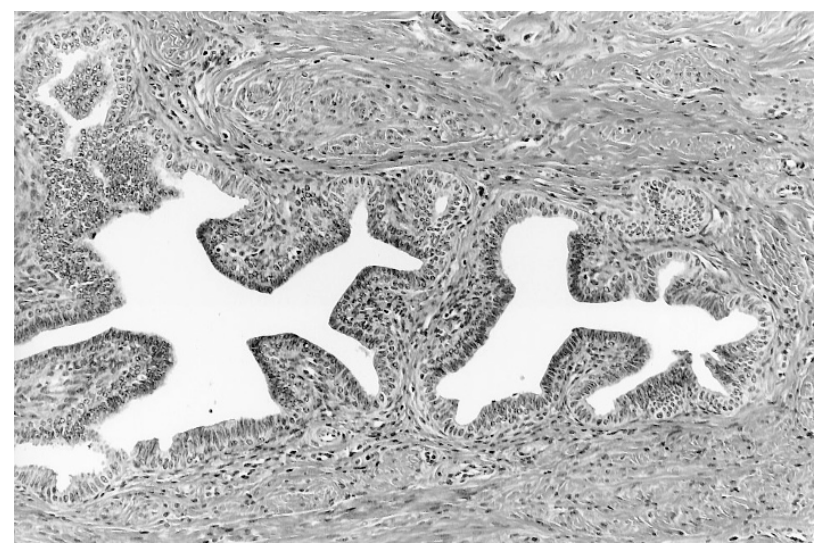

FIGURE 16. Mesonephric hyperplasia. The ductal form of mesonephric hyperplasia is relatively uncommon, consisting of relatively large ducts deep in the stroma, sometimes accompanied by focal tufting of relatively bland epithelial cells. Periodic acid-Schiff-positive luminal secretion is often absent in this form of mesonephric hyperplasia. large, clear vacuoles (72). Individual cell cytoplasm protrudes into glandular lumina, resulting in a hobnail appearance. The distinction from clear cell carcinoma is based on the constellation of history of pregnancy, paucity of mitoses, and absence of invasion or the tubulocystic or solid patterns of clear cell carcinoma.

\section{THOUGHTS ABOUT THE LIMITS OF CERVICAL CONE AND BIOPSY IN THE DIAGNOSIS AND MANAGEMENT OF GLANDULAR LESIONS}

Although the diagnosis of invasive adenocarcinoma sometimes can be made on small, superficial cervical biopsies, it often cannot be excluded even in cone biopsies, particularly when AIS extends to involve the margin of excision. There is unresolved controversy about the significance of margins in cone biopsies for AIS. The lesion may be multifocal, and a recent study (73) found residual AIS in the hysterectomy specimen in $30 \%$ of patients with

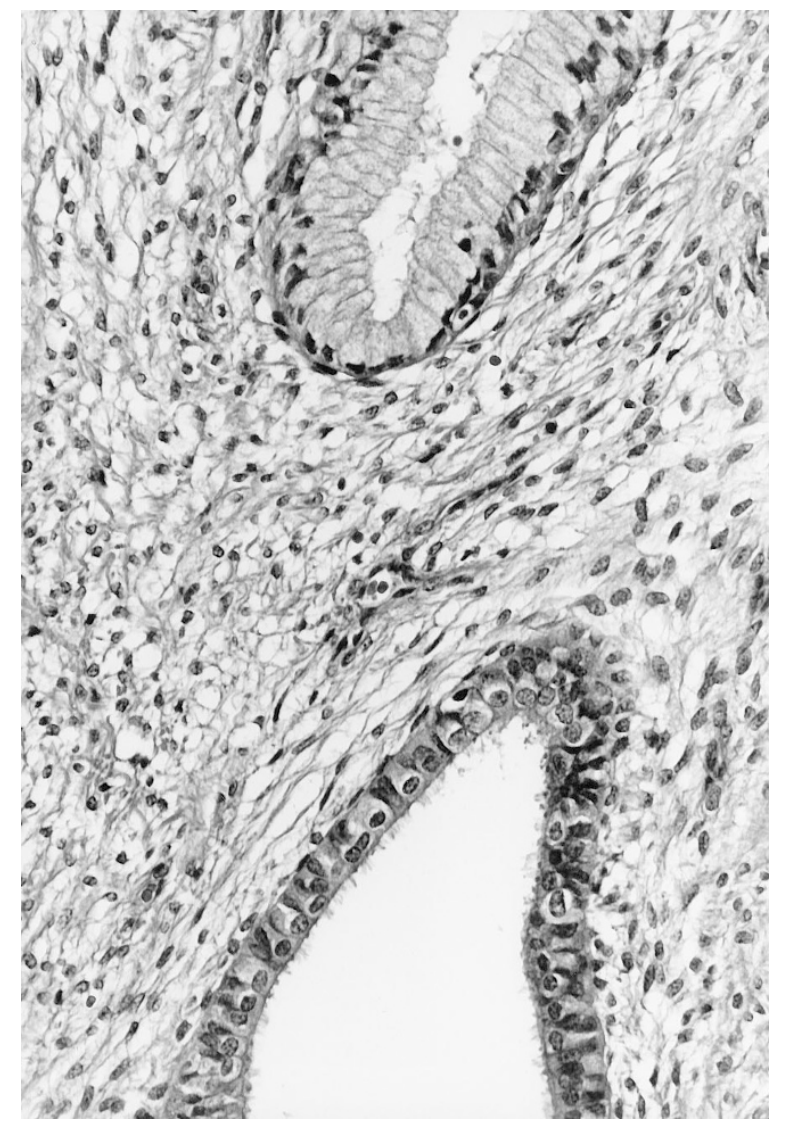

FIGURE 17. Tubal metaplasia. Ciliated and nonciliated non-mucinsecreting columnar cells are a normal component of the upper endocervical canal and may be seen lining part or all of glands. The striking difference in appearance from adjacent mucin-secreting endocervical glands may suggest the possibility of adenocarcinoma in $s i t u$, but the paucity of mitotic figures, relatively bland cytology, and presence of cilia help to confirm the diagnosis. However, it must be acknowledged that in some cases, a clear distinction of adenocarcinoma in situ from atypical tubal metaplasia may be impossible. 
negative margins in the cone biopsy compared with $56 \%$ of patients with a positive endocervical margin in the cone biopsy. However, no patients with a distance greater than $10 \mathrm{~mm}$ from AIS to cone biopsy margin had residual AIS in the hysterectomy specimen, suggesting that this measurement may be important in guiding clinical management.

Villoglandular adenocarcinomas may be accompanied by a conventional adenocarcinoma in their deep aspect, but superficial biopsies may not even contain areas of unequivocal tissue invasion. MDA often cannot be diagnosed confidently in superficial biopsies, and a request for additional tissue in difficult cases may yield more obvious areas of stromal invasion or cytologic atypia. Endometrioid adenocarcinomas in the cervical biopsy may be metastatic from the endometrium. Vimentin positivity provides support for that site of origin, and endometrial sampling in which it is admixed with hyperplasia may confirm it.

\section{REFERENCES}

1. Kurman R, Norris H, Wilkinson E. Tumors of the cervix, vagina, and vulva. Vol. 4. Washington, DC: Armed Forces Institute of Pathology; 1992.

2. Friedell G, McKay D. Adenocarcinoma in situ of the endocervix. Cancer 1953;6:887-97.

3. Christopherson W, Nealon N, Gray L. Noninvasive precursor lesions of adenocarcinoma and mixed adenosquamous carcinoma of the cervix uteri. Cancer 1979;44:975-83.

4. Qizilbash A. In-situ and microinvasive adenocarcinoma of the uterine cervix. Am J Clin Pathol 1975;64:155-70.

5. Liao SY, Brewer C, Zavada J, Pastorek J, Pastorekova S, Manetta A, et al. Identification of the MN antigen as a diagnostic biomarker of cervical intraepithelial squamous and glandular neoplasia and cervical carcinomas. Am J Pathol 1994;145(3):598-609.

6. Jaworski R. Endocervical glandular dysplasia, adenocarcinoma in situ, and early invasive (microinvasive) adenocarcinoma of the uterine cervix. Semin Diagn Pathol 1990;7: 190-205.

7. Casper G, Ostor A, Quinn M. A clinicopathologic study of glandular dysplasia of the cervix. Gynecol Oncol 1997;64: $166-70$.

8. Gompel C, Silverberg S. Pathology in gynecology and obstetrics. Philadelphia: Lippincott; 1994.

9. Brown LJ, Wells M. Cervical glandular atypia associated with squamous intraepithelial neoplasia: a premalignant lesion? J Clin Pathol 1986;39(1):22-8.

10. Gloor E, Hurlimann J. Cervical intraepithelial glandular neoplasia (adenocarcinoma in situ and glandular dysplasia): a correlative study of 23 cases with histologic grading, histochemical analysis of mucins, and immunohistochemical determination of the affinity for four lectins. Cancer 1986;58(6): 1272-80.

11. Clement P, Young R. Deep Nabothian cysts of the uterine cervix. Int J Gynecol Pathol 1989;8:340-8.

12. Fluhmann C. Focal hyperplasia (tunnel clusters) of the cervix uteri. Obstet Gynecol 1961;17:206-14.

13. Clement P, Young R. Tumors and tumorlike lesions of the uterine corpus and cervix. In: Roth L, editor. Contemporary issues in surgical pathology. Vol. 19. New York: Churchill Livingstone; 1993. p. 486.
14. Yeh IT, Li Volsi VA, Noumoff JS. Endocervical carcinoma. Pathol Res Pract 1991;187(2-3):129-44.

15. Noda K, Kimura K, Ikeda M, Teshima K. Studies on the histogenesis of cervical adenocarcinoma. Int J Gynecol Pathol 1983;1:336-46.

16. Fu Y, Reagan J. Pathology of the uterine cervix, vagina, and vulva. Vol. 21. Philadelphia: W.B. Saunders; 1989.

17. Burghardt E. Microinvasive carcinoma in gynaecological pathology. Clin Gynaecol Obstet 1984;11:239-44.

18. Buscema J, Woodruff J. Significance of neoplastic abnormalities in endocervical epithelium. Gynecol Oncol 1984;17:356-62.

19. Ostor A, Rome R, Quinn M. Microinvasive adenocarcinoma of the cervix: a clinicopathologic study of 77 women. Obstet Gynecol 1997;89(1):88-93.

20. Berek J, Hacker N, Fu Y, Sokale J, Leuchter R, Lagasse L. Adenocarcinoma of the uterine cervix: histologic variables associated with lymph node metastasis and survival. Obstet Gynecol 1985;65:46-52.

21. Teshima S, Shimosato Y, Kishi K, Kasamatsu T, Ohmi K, Uei Y. Early stage adenocarcinoma of the uterine cervix: histopathologic analysis with consideration of histogenesis. Cancer 1985;56(1):167-72.

22. Kaspar HG, Dinh TV, Doherty MG, Hannigan EV, Kumar D. Clinical implications of tumor volume measurement in stage I adenocarcinoma of the cervix. Obstet Gynecol 1993;81(2): 296-300.

23. Vesterinen E, Forss M, Nieminen U. Increase of cervical adenocarcinoma: a report of 520 cases of cervical carcinoma including 112 tumors with glandular elements. Gynecol Oncol 1989;33(1):49-53.

24. Peters RK, Chao A, Mack TM, Thomas D, Bernstein L, Henderson BE. Increased frequency of adenocarcinoma of the uterine cervix in young women in Los Angeles County. J Natl Cancer Inst 1986;76(3):423-8.

25. Schwartz S, Weiss N. Increased incidence of adenocarcinoma of the cervix in young women in the United States. Am J Epidemiol 1986;124:1045-7.

26. Brinton LA, Huggins GR, Lehman HF, Mallin K, Savitz DA, Trapido E, et al. Long-term use of oral contraceptives and risk of invasive cervical cancer. Int J Cancer 1986;38(3):39944.

27. Brinton LA, Tashima KT, Lehman HF, Levine RS, Mallin K, Savitz DA, et al. Epidemiology of cervical cancer by cell type. Cancer Res 1987;47(6):1706-11.

28. Okagaki T, Tase T, Twiggs LB, Carson LF. Histogenesis of cervical adenocarcinoma with reference to human papillomavirus-18 as a carcinogen. J Reprod Med 1989;34(9): 639-44.

29. Farnsworth A, Laverty C, Stoler MH. Human papillomavirus messenger RNA expression in adenocarcinoma in situ of the uterine cervix. Int J Gynecol Pathol 1989;8(4):321-30.

30. Tase T, Okagaki T, Clark BA, Twiggs LB, Ostrow RS, Faras AJ. Human papillomavirus DNA in glandular dysplasia and microglandular hyperplasia: presumed precursors of adenocarcinoma of the uterine cervix. Obstet Gynecol 1989;73(6): 1005-8.

31. Duggan MA, McGregor SE, Benoit JL, Inoue M, Nation JG, Stuart GC. The human papillomavirus status of invasive cervical adenocarcinoma: a clinicopathological and outcome analysis. Hum Pathol 1995;26(3):319-25.

32. Milde-Langosch K, Schreiber C, Becker G, Loning T, Stegner HE. Human papillomavirus detection in cervical adenocarcinoma by polymerase chain reaction. Hum Pathol 1993; 24(6):590-4.

33. Yamakawa Y, Forslund O, Teshima H, Hasumi K, Kitagawa T, Hansson BG. Human papillomavirus DNA in adenocarcinoma and adenosquamous carcinoma of the uterine cervix detected by polymerase chain reaction (PCR). Gynecol Oncol 1994;53:190-5. 
34. Chilvers C, Mant D, Pike M. Cervical adenocarcinoma and oral contraceptives. Br J Med (Clin Res Ed) 1987;295:1446-7.

35. Vessey M, Lawless M, McPherson K, Yeates D. Neoplasia of the cervix uteri and contraceptive use: a possible adverse effect of the pill. Lancet 1983;2:930-4.

36. Dallenbach-Hellweg G. On the origin and histologic structure of adenocarcinoma of the endocervix in women under 50 years of age. Pathol Res Pract 1984;179:38-50.

37. Ursin G, Peters RK, Henderson BE, d'Ablaing G III, Monroe KR, Pike MC. Oral contraceptive use and adenocarcinoma of cervix. Lancet 1994;344(8934):1390-4.

38. Thomas DB, Ray RM. Oral contraceptives and invasive adenocarcinomas and adenosquamous carcinomas of the uterine cervix: the World Health Organization Collaborative Study of Neoplasia and Steroid Contraceptives. Am J Epidemiol 1996;144(3):281-9.

39. Parazzini F, La Vecchia C. Epidemiology of adenocarcinoma of the cervix. Gynecol Oncol 1990;39:40-6.

40. Look KY, Brunetto VL, Clarke-Pearson DL, Averette HE, Major FJ, Alvarez RD, et al. An analysis of cell type in patients with surgically staged stage IB carcinoma of the cervix: a Gynecologic Oncology Group study. Gynecol Oncol 1996;63: 304-11.

41. Dabbs DJ, Sturtz K, Zaino RJ. The immunohistochemical discrimination of endometrioid adenocarcinomas. Hum Pathol 1996;27(2):172-7.

42. Young RH, Scully RE. Villoglandular papillary adenocarcinoma of the uterine cervix: a clinicopathologic analysis of 13 cases. Cancer 1989;63(9):1773-9.

43. Jones MW, Silverberg SG, Kurman RJ. Well-differentiated villoglandular adenocarcinoma of the uterine cervix: a clinicopathological study of 24 cases. Int J Gynecol Pathol 1993; 12(1):1-7.

44. Kaku T, Kamura T, Shigematsu T, Sakai K, Nakanami N, Uehira $\mathrm{K}$, et al. Adenocarcinoma of the uterine cervix with predominantly villoglandular papillary growth pattern. Gynecol Oncol 1997;64(1):147-52.

45. Michael H, Sutton G, Hull MT, Roth LM. Villous adenoma of the uterine cervix associated with invasive adenocarcinoma: a histologic, ultrastructural, and immunohistochemical study. Int J Gynecol Pathol 1986;5(2):163-9.

46. Kaku T, Enjoji M. Extremely well-differentiated adenocarcinoma (adenoma malignum) of the cervix. Int J Gynecol Pathol 1983;2:28-41.

47. Kaminski P, Norris H. Minimal deviation carcinoma (adenoma malignum) of the cervix. Int J Gynecol Pathol 1983;2:14152.

48. Gilks C, Young R, Aguirre P, DeLellis R, Scully R. Adenoma malignum (minimal deviation adenocarcinoma) of the uterine cervix. Am J Surg Pathol 1989;13:717-29.

49. Michael H, Grawa L, Kraus F. Minimal deviation endocervical adenocarcinoma: clinical and histologic features, immunohistochemical staining for CEA, and differentiation from confusing benign lesions. Int J Gynecol Pathol 1984;3:26176.

50. Young RH, Scully RE. Minimal-deviation endometrioid adenocarcinoma of the uterine cervix: a report of five cases of a distinctive neoplasm that may be misinterpreted as benign. Am J Surg Pathol 1993;17(7):660-5.

51. Gilks CB, Clement PB. Papillary serous adenocarcinoma of the uterine cervix: a report of three cases. Mod Pathol 1992; 5(4):426-31.

52. Zhou C, Gilks CB, Hayes M, Clement PB. Papillary serous carcinoma of the uterine cervix: a clinicopathologic study of 17 cases. Am J Surg Pathol 1998;22:113-20.

53. Ferry JA, Scully RE. Mesonephric remnants, hyperplasia, and neoplasia in the uterine cervix: a study of 49 cases. Am J Surg Pathol 1990;14(12):1100-11.
54. Valente PT, Susin M. Cervical adenocarcinoma arising in florid mesonephric hyperplasia: report of a case with immunocytochemical studies. Gynecol Oncol 1987;27(1):58-68.

55. Lang G, Dallenbach-Hellweg G. The histogenetic origin of cervical mesonephric hyperplasia and mesonephric adenocarcinoma of the uterine cervix studied with immunohistochemical methods. Int J Gynecol Pathol 1990;9(2):145-57.

56. Ferry JA, Scully RE. "Adenoid cystic" carcinoma and adenoid basal carcinoma of the uterine cervix: a study of 28 cases. Am J Surg Pathol 1988;12(2):134-44.

57. Grayson W, Taylor L, Cooper K. Adenoid cystic and adenoid basal carcinoma of the uterine cervix. Am J Surg Pathol 1999;23:448-58.

58. Cina SJ, Richardson MS, Austin RM, Kurman RJ. Immunohistochemical staining for Ki-67 antigen, carcinoembryonic antigen, and p53 in the differential diagnosis of glandular lesions of the cervix. Mod Pathol 1997;10(3):176-80.

59. Fluhmann C. The glandular structures of the cervix uteri. Surg Gynecol Obstet 1958;106:715-23.

60. Segal GH, Hart WR. Cystic endocervical tunnel clusters: a clinicopathologic study of 29 cases of so-called adenomatous hyperplasia. Am J Surg Pathol 1990;14(10):895-903.

61. Jones MA, Young RH, Scully RE. Diffuse laminar endocervical glandular hyperplasia: a benign lesion often confused with adenoma malignum (minimal deviation adenocarcinoma). Am J Surg Pathol 1991;15(12):1123-9.

62. Taylor H, Irey N, Norris H. Atypical endocervical hyperplasia in women taking oral contraceptives. JAMA 1967;202:185-90.

63. Kyriakos M, Kempson R, Konikov N. A clinical and pathologic study of endocervical lesions associated with oral contraceptives. Cancer 1968;22:99-109.

64. Greeley C, Schroeder S, Silverberg SG. Microglandular hyperplasia of the cervix: a true "pill" lesion? Int J Gynecol Pathol 1995;14(1):50-4.

65. Young RH, Scully RE. Atypical forms of microglandular hyperplasia of the cervix simulating carcinoma: a report of five cases and review of the literature. Am J Surg Pathol 1989; 13(1):50-6.

66. Jones MA, Andrews J, Tarraza HM. Mesonephric remnant hyperplasia of the cervix: a clinicopathologic analysis of 14 cases. Gynecol Oncol 1993;49(1):41-7.

67. Jonasson JG, Wang HH, Antonioli DA, Ducatman BS. Tubal metaplasia of the uterine cervix: a prevalence study in patients with gynecologic pathologic findings. Int J Gynecol Pathol 1992;11(2):89-95.

68. Suh KS, Silverberg SG. Tubal metaplasia of the uterine cervix. Int J Gynecol Pathol 1990;9(2):122-8.

69. McCluggage WG, Maxwell P, McBride HA, Hamilton PW, Bharucha H. Monoclonal antibodies Ki-67 and MIB1 in the distinction of tuboendometrial metaplasia from endocervical adenocarcinoma and adenocarcinoma in situ in formalin-fixed material. Int J Gynecol Pathol 1995;14(3):20916.

70. Oliva E, Clement PB, Young RH. Tubal and tuboendometrioid metaplasia of the uterine cervix: unemphasized features that may cause problems in differential diagnosis: a report of 25 cases. Am J Clin Pathol 1995;103(5):61823.

71. Schlesinger C, Silverberg SG. Endocervical adenocarcinoma in situ of tubal type and its relation to atypical tubal metaplasia. Int J Gynecol Pathol 1999;18:1-4.

72. Cove H. The Arias-Stella reaction occurring in the endocervix in pregnancy. Am J Surg Pathol 1979;3:567-8.

73. Goldstein NS, Mani A. The status and distance of cone biopsy margins as a predictor of excision adequacy for endocervical adenocarcinoma in situ. Am J Clin Pathol 1998; 109(6):727-32. 